\title{
Profit bridges that disambiguate impacts of currency fluctuations from other marketing variables
}

\author{
Tim J. Smith ${ }^{1} \cdot$ Kyle T. Westra ${ }^{1} \cdot$ Nathan L. Phipps ${ }^{1}$
}

Received: 9 March 2021 / Accepted: 4 November 2021 / Published online: 29 November 2021

(c) The Author(s) 2021

\begin{abstract}
We extend the normalized approach to constructing profit bridges proffered in a recent paper to examine the impact of currency exchange rate fluctuations within a multinational corporation. In doing so, we describe a profit bridge that would measure corporate performance distinct from that which would measure the performance of business units, including metrics for the impact of volume, price, variable cost, offering mix, and exchange rate changes.
\end{abstract}

Keywords Profit bridge $\cdot$ Price-volume-mix analysis $\cdot$ Currency fluctuation $\cdot$ Profit variance analysis $\cdot$ Analytic modeling . Attribution

\section{Introduction}

When comparing the profit performance of a company between periods, decision makers often seek to attribute the origin of changes in profits to changes in various business variables. For a multinational corporation, one of the variables that should be included is the impact of changes in currency exchange rates.

While quantity sold, prices, variable costs, and mix are under the influence of management decisions, currency exchange rates are a completely exogenous business variable. Favorable exchange rate changes can introduce a profit windfall, and unfavorable exchange rate changes can introduce a shortfall. While the impacts of fluctuating exchange rates might be countered by some managerial decisions, decision makers often want to examine the impact of exchange rate changes distinctly from the impact of changes in other business variables.

In this paper, we extend the normalized approach to constructing profit bridges proffered in a recent paper to

Tim J. Smith

tsmith@wiglafpricing.com

Kyle T. Westra

ktwestra@wiglafpricing.com

Nathan L. Phipps

nphipps@wiglafpricing.com

1 Wiglaf Pricing, 2607 W. Augusta Blvd, Chicago, IL 60622, USA examine the impact of exchange rate fluctuations within a multinational corporation. This will produce a profit bridge that measures the impact of changes in selling quantities, prices, variable costs, offering mix, and exchange rates.

Because multinational corporations often have distinct business units, we construct profit bridges at both the corporate and the business unit levels. While the overall change in profit at the corporate level is the sum of the change in profits across all business units, we detect and demonstrate that the sum across all business units of an individual profit bridge element would differ from its parallel at the corporate level and clarify why this is appropriate.

This profit bridge can be used for investor reporting and measuring the performance of individual business variables. While alone, a profit bridge cannot definitively state which actions to take, combined with other measurements and business intelligence, it can lead to better decision-making.

The period of analysis could be a year, quarter, month, week, or day compared to an equal period in the past. This will lead to studies of this year compared to last year, this quarter compared to last quarter, or this quarter compared to the same quarter last year of a business unit or the corporation overall.

This approach can be extended to produce a margin bridge in addition to a profit bridge. Margin bridges are typically expressed in percentages, while the profit bridge is in terms of dollars, euros, or other currency.

This profit bridge is also akin to the profit variance analysis in financial accounting literature. A major difference is 
that with the profit bridge we are looking to measure the impact of marketing variable changes in different business periods, whereas much of the financial accounting literature has been focused on variances between budgeted performance and actual performance.

Implementation of these equations can be done via spreadsheet analysis, various programming languages, or specialized software.

The decomposition of profits between any two periods offered herein meets the four criteria of: (1) the sum of the measurements equaling the actual change of profits, (2) the individual measurements are clear and discernable as it relates to actual changes in underlying marketing variables, (3) the measurements provide sufficient specificity so as to enable the evaluation of the outcomes of specific strategies, and (4) the measurements present mirror symmetry such that going forward in time produces equal and opposite measurements as going backwards in time does.

\section{Related literature}

There have been many efforts in constructing a profit bridge or margin analysis, and it has been given a variety of names including variance analysis, price-volume-mix analysis, and profit analyzer.

Much of the academic discussion regarding profit bridges appears in the financial accounting literature related to variance analysis between budgeted performance and actual performance. Calas noted the importance of sales mix in conducting a variance analysis (Calas 1971). Extensive discussion was held regarding the analysis of the joint variance of both quantity and price or variable cost between budgeted and actual performance (McIntyre 1976) (McIntyre 1978) (Piper 1977). Mitchell and Olsen continued with the approach of McIntyre and others in examining the impact of exogenous marketing variables (Mitchell and Olsen 2003).

Shank and Churchill avoided the challenging joint variance term in their approach to comparing actual to budgeted performance by alternating between using the budgeted or actual performance as the point of reference (Shank 1977). Hulbert and Toy expanded this study to include issues of market share (Hulbert and Toy 1977). More recently, Albers noted the importance of using a variance analysis in marketing control and built upon the same basic concept of a budget versus actual performance (Albers 1998).

The variance analysis in financial accounting with alternating points of reference between budgeted and reference was taken up by management consultants and software vendors as a starting point for defining a profit bridge, or its percentage-based analog, margin analysis. A patent used similar alternating points of reference between time periods for stating equations for a margin analyzer (Early 2013). A similar set of equations for a profit bridge can be found in an article on LearnAccountingFinance.com (LearnAccountingFinance.com 2018). Coskun provided a working example using similar logic on LinkedIn (Coskun 2016).

In contrast, a recent paper provided a normalized approach to constructing a profit bridge, also referred to as a price-volume-mix analysis. This normalized approach used the product of interperiod averages and interperiod changes of business variables to quantify the impact of changes in selling quantity, prices, variable costs, and mix (Smith 2021).

The major differences between the approach taken by Shank and Churchill and that by Smith lies in defining the point of reference. As stated, the Shank and Churchill approach alternated between using the budgeted or actual performance as the point of reference, whereas that of Smith consistently used the interperiod averages and interperiod changes. For analyzing the difference between budgeted and actual performance, the Smith equations would use the average of the budgeted and actual performance and the changes between the budgeted and actual performance. The result of using the Smith equations is a mirror symmetry between looking forward and backwards in time when comparing two periods or a mirror symmetry between comparing actuals to budget versus budget to actuals, a symmetry which is lacking in the Shank and Churchill approach.

The purpose of this research is to extend the normative decomposition of the profit bridge to include issues of currency exchange rate fluctuations in a multinational company.

\section{Industry examples}

Companies with international and multinational operations frequently comment on foreign exchange effects during their earnings calls, illustrating that such effects are valuable to analysts and investors. While we suspect they are stating the impacts measured using an approach similar to that developed by Shank and Churchill, the actual equations that are used are rarely, if ever, reported. As such, we cannot attest to the accuracy of their statements, but strongly suspect they provide a good approximation of the truth.

For instance, Apple CFO Luca Maestri reported on its company earnings call that Q1 2020 exchange rates were responsible for a $1 \%$ decrease in sales (Vizcaino and McCormcik 2020). McDonald's CFO stated that "foreign currency translation negatively impacted our second quarter [2019] results by $\$ 0.07$ per share" (SA Transcripts 2019). Johnson \& Johnson said on its Q4 2020 results call that "there is an estimated positive impact of foreign currency translation of approximately 200 basis points, resulting in an estimated reported sales growth of between 9.5 and $11.0 \%$... or $\$ 90.5$ billion to $\$ 91.7$ billion” (SA Transcripts 2021). 
The Kyriba Currency Impact Report tracks foreign exchange impacts for over a thousand companies in North American and Europe based on earnings calls. It indicated that "European multinational corporations suffered the brunt of the $\$ 9.82$ billion reported lost due to currency volatility in the third quarter of 2020" (Kyriba Corp. 2021). Illustrating the scale of the issue, it also reported that " 117 North American and European companies reported currency headwinds in Q3 2020. Of those companies, 89 companies quantified their FX impacts" (Kyriba 2021).

\section{Corporate profit bridge}

At the corporate level, where profits may be earned in multiple currencies, the profit bridge can be constructed to measure the impacts of currency fluctuations distinct from those of pricing decisions. This would be useful for many multinational companies where offerings are transacted in local currencies but profits are measured using a global currency.

In many annual reports, executives have reported a windfall or shortfall due to exchange rate changes. A profit bridge that identifies the impact of changing exchange rates distinct from those of pricing decisions would enable investors and managers to quantify and isolate the impact of currency fluctuations. Also, pricing decisions may be made to counter the impact of currency fluctuations. A global profit bridge that disambiguates impacts of currency fluctuations from pricing decisions would enable decision makers to determine how well price changes were managed in the light of currency fluctuations.

The corporate profit bridge which follows would be useful for measuring how prices and variable costs are managed at the overall global level. For a global pricing or procurement function within the corporation, the elements within the corporate profit bridge distinctly measure how prices and variable costs are being managed at the global level. These global metrics would be distinct from local metrics (i.e., the metrics appropriate for measuring how prices and variable costs are measured at the local level), as we will show.

\section{Notation and intraperiod business metrics}

Let us identify transactions with the subscripts of $h$ for individual transaction in period $i$ for offering $j$ in the currency $k$ as shown in Table 1: Subscripts.

Then for a given transaction $h$ in period $i$ of offering $j$ in currency $k$, we have the quantity sold denoted as $\mathrm{Q}_{\mathrm{kjih}}$, the price in local and global currency denoted as $\mathrm{PL}_{\mathrm{kjih}}$ and $\mathrm{PG}_{\mathrm{kjih}}$, respectively, the variable cost in local and global currency denoted as $\mathrm{VL}_{\mathrm{kjih}}$ and $\mathrm{VG}_{\mathrm{kjih}}$, respectively, and the exchange rate denoted as $\mathrm{E}_{\mathrm{kjih}}$, as shown in Table 2: Notation.
Table 1 Subscripts

\begin{tabular}{ll}
\hline & Subscript \\
\hline Transaction & $\mathrm{h}$ \\
Period (1 or 2) & $\mathrm{i}$ \\
Offering & $\mathrm{j}$ \\
Country or Business Unit & $\mathrm{k}$ \\
\hline
\end{tabular}

Table 2 Notation

\begin{tabular}{ll}
\hline & Term \\
\hline Quantity sold & $Q_{k j i h}$ \\
Price in Local currency & $P L_{k j i h}$ \\
Price in Global currency & $P G_{k j i h}$ \\
Variable Cost in Local Currency & $V L_{k j h}$ \\
Variable Cost in Global Currency & $V G_{k j i h}$ \\
Exchange Rate & $E_{k j i h}$ \\
\hline
\end{tabular}

Within a period, we identify the overall quantity sold, prices, and variable costs of individual offerings in a given currency by dropping the last subscript. Thus, the quantity sold in period $i$ of offering $j$ and currency $k, \mathrm{Q}_{\mathrm{kji}}$, is simply the sum across all transactions $h$, as in Eq. 1.

$Q_{k j i}=\sum_{h} Q_{k j i h}$

As for prices and variable costs, managers would recognize the relevant price and variable cost for an offering across a period as the weighted average price and variable cost. Quantity weightings, $\mathrm{W}_{\mathrm{kjih}}$, are used to define the weighted average prices and variable costs of individual offerings in a given currency and period. These weightings are written in Eq. 2.

$W_{k j h}=\frac{Q_{k j h}}{\sum_{h} Q_{k j h}}$

Thus, we identify the weighted average price in local and global currency in period $i$ of offering $j$ and currency $k, \mathrm{PL}_{\mathrm{kji}}$ and $\mathrm{PG}_{\mathrm{kji}}$, in Eqs. 3 and 4, respectively.

$P L_{k j i}=\sum_{h} W_{k j i h} \cdot P L_{k j i h}$

$P G_{k j i}=\sum_{h} W_{k j i h} \cdot P L_{k j i h} \cdot E_{k j i h}$

We identify the weighted average variable costs in local and global currency in period $i$ of offering $j$ and currency $k$, $\mathrm{VL}_{\mathrm{kji}}$ and $\mathrm{VG}_{\mathrm{kji}}$, in Eqs. 5 and 6, respectively. 
$V L_{k j i}=\sum_{h} W_{k j i h} \cdot V L_{k j i h}$

$V G_{k j i}=\sum_{h} W_{k j i h} \cdot V L_{k j i h} \cdot E_{k j i h}$

To measure the impact of currency fluctuations on profits, we require the weighted average exchange rates. Using Eqs. 3 through 6, we identify the weighted average exchange rates over the period. The weighted average exchange rates for prices and variable costs, $\mathrm{EP}_{\mathrm{kji}}$ and $\mathrm{EV}_{\mathrm{kji}}$, respectively, would be simply the weighted average price or variable cost in global currency divided by that in local currency across transactions within a period. See Eqs. 7 and 8.

$E P_{k j i}=\frac{P G_{k j i}}{P L_{k j i}}=\frac{\sum_{h} W_{k j i h} \cdot P L_{k j i h} \cdot E_{k j i h}}{\sum_{h} W_{k j i h} \cdot P L_{k j i h}}$

$E V_{k j i}=\frac{V G_{k j i}}{V L_{k j i}}=\frac{\sum_{h} W_{k j i h} \cdot V L_{k j i h} \cdot E_{k j h}}{\sum_{h} W_{k j i h} \cdot V L_{k j i h}}$

Notice that the weighted average exchange rate differs between that for prices and that for variable costs. The difference arises not because the exchange rate is different between these variables on individual transactions, but because the monetary weightings used to quantify the weighted average exchange rates within a period vary. Thus, two weighted average exchange rates are required to accurately identify the impact of changes in exchange rates. In practice, one would expect these two exchange rates, $\mathrm{EP}_{\mathrm{kji}}$ and $\mathrm{EV}_{\mathrm{kj}}$, to be similar, but small variations may arise due to small differences in the weightings.

To measure the impact of changes in offering mix sold on profits, we require the mix weighting for individual offering $j$ in period $i$ and currency $k$. The mix weightings at the local level will be different from those at the global level.

Specifically, for an individual business unit, the offering mix sold in that country is independent from that sold in other business units. As such, the local mix weightings only require the denominator to sum over all products $j$ sold in that business unit in a given period. See Eq. 9 for the definition of the local mix weighting $\mathrm{ML}_{\mathrm{kji}}$.

$M L_{k j i}=\frac{Q_{k j i}}{\sum_{j} Q_{k j i}}$

In contrast, for the overall corporate performance, the offering mix sold must consider the sales of all offerings across all business units. As such, the global mix weightings require the denominator to sum over all business units $k$ and products $j$ sold in that period. See Eq. 10 for the definition of the global mix weighting, $\mathrm{MG}_{\mathrm{kji}}$.
$M G_{k j i}=\frac{Q_{k j i}}{\sum_{k j} Q_{k j i}}$

\section{Defining the corporate profit bridge in light of currency fluctuations}

The generalized change in corporate profits between two periods, $\Delta R G$, is expressed in Eq. 11 using the standard profit equation of the firm but summing across currencies and offerings and taking the difference in profits between periods $i=1$ and $i=2$.

$$
\begin{aligned}
\Delta R G= & \sum_{k j}\left[Q_{k j 2} \cdot\left(P L_{k j 2} \cdot E P_{k j 2}-V L_{k j 2} \cdot E V_{k j 2}\right)\right. \\
& \left.-Q_{k j 1} \cdot\left(P L_{k j 1} \cdot E P_{k j 1}-V L_{k j 1} \cdot E V_{k j 1}\right)\right]
\end{aligned}
$$

As we will demonstrate, the generalized change in corporate profits can be expressed as the profit bridge found in Eq. 12 wherein individual terms within this profit bridge measure the performance of the corporation in managing specific business variables in light of currency fluctuations.

$\Delta R G=I Q G+I P G+I V G+I M G+I E G$

where IQG measures the impact of changes in quantity sold, IPG measures the impact of changes in prices, IVG measures the impact of changes in variable costs, IMG measures the impact of changes in offering mix, and IEG measures the impact of changes in exchange rates.

IQG is defined as the global change in quantity sold times the difference in the interperiod global average price and variable cost across all products. Thus, IQG can alternatively be written conceptually, in detail using global prices, or in detail using local prices and exchange rates as

$$
\begin{aligned}
I Q G= & \Delta Q \cdot(\overline{P G}-\overline{V G}) \\
= & \sum_{k, j}\left(Q_{k j 2}-Q_{k j 1}\right) \cdot \sum_{k, j}\left(\frac{M G_{k j 2} \cdot P G_{k j 2}+M G_{k j 1} \cdot P G_{k j 1}}{2}\right. \\
& \left.-\frac{M G_{k j 2} \cdot V G_{k j 2}+M G_{k j 1} \cdot V G_{k j 1}}{2}\right) \\
= & \sum_{k, j}\left(Q_{k j 2}-Q_{k j 1}\right) \cdot \sum_{k, j}\left(\frac{M G_{k j 2} \cdot P L_{k j 2} \cdot E P_{k j 2}+M G_{k j 1} \cdot P L_{k j 1} \cdot E P_{k j 1}}{2}\right. \\
& \left.-\frac{M G_{k j 2} \cdot V L_{k j 2} \cdot E V_{k j 2}+M G_{k j 1} \cdot V L_{k j 1} \cdot E V_{k j 1}}{2}\right)
\end{aligned}
$$

IPG is defined as the interperiod average global quantity sold times the sum product of the changes in local prices, interperiod average global mix contribution, and the interperiod weighted average exchange rate for prices. Thus, IPG can be written conceptually or in detail using local prices and exchange rates as 
$I P G=\bar{Q} \cdot \sum_{k, j} \Delta P L_{k j} \cdot \overline{M G_{k j}} \cdot \overline{E P_{k j}}=\sum_{k, j} \frac{Q_{k j 2}+Q_{k j 1}}{2} \cdot \sum_{k, j}\left[\left(P L_{k j 2}-P L_{k j 1}\right) \cdot \frac{\left(M G_{k j 2}+M G_{k j 1}\right)}{2} \cdot \frac{\left(E P_{k j 2}+E P_{k j 1}\right)}{2}\right]$

IVG is defined as the negative of the interperiod average global quantity sold times the sum product of the changes in local variable costs, interperiod average global mix contribution, and the interperiod weighted average exchange rate for variable costs. Thus, IVG can be written conceptually or in detail using local variable costs and exchange rates as

\section{Defining the business unit profit bridge within a global corporation in light of currency fluctuations}

The generalized change in business unit profits between two periods, $\Delta \mathrm{RG}_{\mathrm{k}}$, is expressed in Eq. 18 using the standard

$I V G=-\bar{Q} \cdot \sum_{k, j} \Delta V L_{k j} \cdot \overline{M G_{k j}} \cdot \overline{E V_{k j}}=-\sum_{k, j} \frac{Q_{k j 2}+Q_{k j 1}}{2} \cdot \sum_{k, j}\left[\left(V L_{k j 2}-V L_{k j 1}\right) \cdot \frac{\left(M G_{k j 2}+M G_{k j 1}\right)}{2} \cdot \frac{\left(E V_{k j 2}+E V_{k j 1}\right)}{2}\right]$

IMG is defined as the interperiod average global quantity sold times the sum product of the difference in interperiod average global prices and variable costs and the change in global mix contribution between the two periods. Thus, IMG can be written conceptually, in detail using global prices, or in detail using local prices and exchange rates as

$$
\begin{aligned}
I M G= & \bar{Q} \cdot \sum_{k, j}\left(\overline{P G_{k j}}-\overline{V G_{k j}}\right) \cdot \Delta M G_{k j} \\
= & \sum_{k, j} \frac{Q_{k j 2}+Q_{k j 1}}{2} \cdot \sum_{k, j}\left(\frac{P G_{k j 2}+P G_{k j 1}}{2}\right. \\
& \left.-\frac{V G_{k j 2}+V G_{k j 1}}{2}\right) \cdot\left(M G_{k j 2}-M G_{k j 1}\right) \\
= & \sum_{k, j} \frac{Q_{k j 2}+Q_{k j 1}}{2} \cdot \sum_{k, j}\left(\frac{P L_{k j 2} \cdot E P_{k j 2}+P L_{k j 1} \cdot E P_{k j 1}}{2}\right. \\
& \left.-\frac{V L_{k j 2} \cdot E V_{k j 2}+V L_{k j 1} \cdot E V_{k j 1}}{2}\right) \cdot\left(M G_{k j 2}-M G_{k j 1}\right)
\end{aligned}
$$

IEG is defined as the average global quantity sold across the two periods times the sum product of the interperiod average global mix contribution and of the difference in the intraperiod average local price times the change in weighted average exchange rate for prices, and the intraperiod average local variable costs across time times the change in weighted average exchange rate for variable costs. Thus, IEG can be written conceptually or in detail using local prices, variable costs, and exchange rates as

$$
\begin{aligned}
I E G=\bar{Q} & \cdot \sum_{k, j}\left(\overline{P L_{k j}} \cdot \Delta E P_{k j}-\overline{V L_{k j}} \cdot \Delta E V_{k j}\right) \cdot \overline{M G_{k j}} \\
= & \sum_{k j} \frac{Q_{k j 2}+Q_{k j 1}}{2} \cdot \sum_{k, j}\left(\frac{P L_{k j 2}+P L_{k j 1}}{2} \cdot\left(E P_{k j 2}-E P_{k j 1}\right)\right. \\
& \left.-\frac{V L_{k j 2}+V L_{k j 1}}{2} \cdot\left(E V_{k j 2}-E V_{k j 1}\right)\right) \cdot \frac{\left(M G_{k j 2}+M G_{k j 1}\right)}{2}
\end{aligned}
$$

profit equation of the firm but summing across offerings within business unit $k$ and taking the difference in profits between periods $i=1$ and $i=2$ for that business unit. Expressed in terms of the global currency, we would write:

$$
\begin{aligned}
\Delta R G_{k}= & \sum_{j}\left[Q_{k j 2} \cdot\left(P L_{k j 2} \cdot E P_{k j 2}-V L_{k j 2} \cdot E V_{k j 2}\right)\right. \\
& \left.-Q_{k j 1} \cdot\left(P L_{k j 1} \cdot E P_{k j 1}-V L_{k j 1} \cdot E V_{k j 1}\right)\right]
\end{aligned}
$$

As we will demonstrate, the generalized change in business unit profits can be expressed as the profit bridge found in Eq. 19 wherein individual terms within this profit bridge measure the performance of the business unit in managing specific business variables in light of currency fluctuations.

$\Delta R G_{k}=I Q G_{k}+I P G_{k}+I V G_{k}+I M G_{k}+I E G_{k}$

where $\mathrm{IQG}_{\mathrm{k}}$ measures the impact of changes in quantity sold at business unit $k, \mathrm{IPG}_{\mathrm{k}}$ measures the impact of changes in prices at business unit $k, \mathrm{IVG}_{\mathrm{k}}$ measures the impact of changes in variable costs at business unit $k, \mathrm{IMG}_{\mathrm{k}}$ measures the impact of changes in offering mix at business unit $k$, and $\mathrm{IEG}_{\mathrm{k}}$ measures the impact of changes in exchange rates at business unit $k$.

$\mathrm{IQG}_{\mathrm{k}}$ is defined as the change in quantity sold within the business unit times the difference in the business unit interperiod average price and variable cost expressed in global currency. Thus, $\mathrm{IQG}_{\mathrm{k}}$ can alternatively be written conceptually, in detail using global prices, or in detail using local prices and exchange rates as 


$$
\begin{aligned}
I Q G_{k}= & \Delta Q_{k} \cdot\left(\overline{P G_{k}}-\overline{V G_{k}}\right) \\
= & \sum_{j}\left(Q_{k j 2}-Q_{k j 1}\right) \cdot \sum_{j}\left(\frac{M L_{k j 2} \cdot P G_{k j 2}+M L_{k j 1} \cdot P G_{k j 1}}{2}\right. \\
& \left.-\frac{M L_{k j 2} \cdot V G_{k j 2}+M L_{k j 1} \cdot V G_{k j 1}}{2}\right) \\
= & \sum_{j}\left(Q_{k j 2}-Q_{k j 1}\right) \cdot \sum_{j}\left(\frac{M L_{k j 2} \cdot P L_{k j 2} \cdot E P_{k j 2}+M L_{k j 1} \cdot P L_{k j 1} \cdot E P_{k j 1}}{2}\right. \\
& \left.-\frac{M L_{k j 2} \cdot V L_{k j 2} \cdot E V_{k j 2}+M L_{k j 1} \cdot V L_{k j 1} \cdot E V_{k j 1}}{2}\right)
\end{aligned}
$$

IPG $_{k}$ is defined as the interperiod average quantity sold within the business unit times the sum product of the changes in local prices, interperiod average local mix contribution, and the interperiod weighted average exchange rate for prices. Thus, $\mathrm{IPG}_{\mathrm{k}}$ can be written conceptually or in detail using local prices and exchange rates as
$\mathrm{IEG}_{\mathrm{k}}$ is defined as the interperiod average quantity sold within the business unit times the sum product of the interperiod average local mix contribution and of the difference in the intraperiod average local price times the change in weighted average exchange rate for prices, and the intraperiod average local variable costs across time, times the change in weighted average exchange rate for variable costs. Thus, IEG $_{\mathrm{k}}$ can be written conceptually or in detail using local prices and variable costs and exchange rates as

$$
\begin{aligned}
I E G_{k}= & \overline{Q L_{k}} \cdot \sum_{j}\left(\overline{P L_{k j}} \cdot \Delta E P_{k j}-\overline{V L_{k j}} \cdot \Delta E V_{k j}\right) \cdot \overline{M L_{k j}} \\
= & \sum_{j} \frac{Q_{k j 2}+Q_{k j 1}}{2} \cdot \sum_{j}\left(\frac{P L_{k j 2}+P L_{k j 1}}{2} \cdot\left(E P_{k j 2}-E P_{k j 1}\right)\right. \\
& \left.-\frac{V L_{k j 2}+V L_{k j 1}}{2} \cdot\left(E V_{k j 2}-E V_{k j 1}\right)\right) \cdot \frac{\left(M L_{k j 2}+M L_{k j 1}\right)}{2}
\end{aligned}
$$

$I P G_{k}=\overline{Q_{k}} \cdot \sum_{j} \Delta P L_{k j} \cdot \overline{M L_{k j}} \cdot \overline{E P_{k j}}=\sum_{j} \frac{Q_{k j 2}+Q_{k j 1}}{2} \cdot \sum_{j}\left(P L_{k j 2}-P L_{k j 1}\right) \cdot \frac{\left(M L_{k j 2}+M L_{k j 1}\right)}{2} \cdot \frac{\left(E P_{k j 2}+E P_{k j 1}\right)}{2}$

$\mathrm{IVG}_{\mathrm{k}}$ is defined as the negative of the interperiod average quantity sold within the business unit times the sum product of the changes in local variable costs, interperiod average local mix contribution, and the interperiod weighted average exchange rate for variable costs. Thus, $\mathrm{IVG}_{\mathrm{k}}$ can be written conceptually or in detail using local variable costs and exchange rates as

\section{Comparing corporate profit bridge to business unit profit bridge}

It might be tempting to assume the corporate profit bridge is simply the sum across business units of the business unit profit bridge. However, it is not.

$I V G_{k}=-\overline{Q_{k}} \cdot \sum_{j} \Delta V L_{k j} \cdot \overline{M L_{k j}} \cdot \overline{E V_{k j}}=-\sum_{j} \frac{Q_{k j 2}+Q_{k j 1}}{2} \cdot \sum_{j}\left(V L_{k j 2}-V L_{k j 1}\right) \cdot \frac{\left(M L_{k j 2}+M L_{k j 1}\right)}{2} \cdot \frac{\left(E V_{k j 2}+E V_{k j 1}\right)}{2}$

$\mathrm{IMG}_{\mathrm{k}}$ is defined as the interperiod average quantity sold within the business unit times the sum product of the difference in interperiod average global prices and variable costs and the change in local mix contribution between the two periods. Thus, $\mathrm{IMG}_{\mathrm{k}}$ can be written conceptually, in detail using global prices, or in detail using local prices and exchange rates as

$$
\begin{aligned}
I M G_{k}=\overline{Q_{k}} & \cdot \sum_{j}\left(\overline{P G_{k j}}-\overline{V G_{k j}}\right) \cdot \Delta M L_{k j} \\
= & \sum_{j} \frac{Q_{k j 2}+Q_{k j 1}}{2} \cdot \sum_{j}\left(\frac{P G_{k j 2}+P G_{k j 1}}{2}\right. \\
& \left.-\frac{V G_{k j 2}+V G_{k j 1}}{2}\right) \cdot\left(M L_{k j 2}-M L_{k j 1}\right) \\
= & \sum_{j} \frac{Q_{k j 2}+Q_{k j 1}}{2} \cdot \sum_{j}\left(\frac{P L_{k j 2} \cdot E P_{k j 2}+P L_{k j 1} \cdot E P_{k j 1}}{2}\right. \\
& \left.-\frac{V L_{k j 2} \cdot E V_{k j 2}+V L_{k j 1} \cdot E V_{k j 1}}{2}\right) \cdot\left(M L_{k j 2}-M L_{k j 1}\right)
\end{aligned}
$$

While the same overall change in profit would be measured between these two approaches, that is that $\Delta \mathrm{RG}$ is equal to the sum across all $k$ of $\Delta \mathrm{RG}_{\mathrm{k}}$, the individual terms within the profit bridges would indicate different measurements, that is that IXG is not the same as the sum across all $k$ of $\mathrm{IXG}_{\mathrm{k}}$, where X is either Q, P, V, M, or E.

The difference arises from the differing mix definitions between the global and local level. The global mix accounts for changing the share of offerings sold between business units. The local mix does not as it only accounts for changing the share of offerings sold within an individual business unit.

One might address differences between the sum of the business unit profit bridges and the corporate profit bridge by adding a new business unit mix term to account for changes in sales between business units. Yet then, one would compromise the measurements of multiple impacts of changes in other business variables at the global level. For this reason, we have not taken this approach, but are aware that it can be taken. 
Table 3 Scenario firm

\begin{tabular}{|c|c|c|c|c|c|c|c|c|}
\hline \multirow{3}{*}{$\begin{array}{l}\text { Period } \\
\text { Country } \\
\text { Product }\end{array}$} & \multicolumn{4}{|l|}{1} & \multicolumn{4}{|l|}{2} \\
\hline & \multicolumn{2}{|l|}{ US } & \multicolumn{2}{|l|}{$\mathrm{CZ}$} & \multicolumn{2}{|l|}{ US } & \multicolumn{2}{|l|}{$\mathrm{CZ}$} \\
\hline & A & B & A & B & A & B & A & B \\
\hline Quantity sold & 25 & 50 & 25 & 50 & 27 & 60 & 25 & 55 \\
\hline Price local & 20 & 10 & 400 & 200 & 22 & 9 & 425 & 220 \\
\hline Variable cost local & 3 & 6 & 60 & 120 & 4 & 6 & 73 & 109 \\
\hline Price exchange rate & 1.000 & 1.000 & 0.050 & 0.050 & 1.000 & 1.000 & 0.045 & 0.045 \\
\hline Variable cost exchange rate & 1.000 & 1.000 & 0.055 & 0.055 & 1.000 & 1.000 & 0.050 & 0.050 \\
\hline Business unit profit in local currency & 625.0 & & $12,500.0$ & & 666.0 & & $14,907.8$ & \\
\hline Corporate profit in global currency & 1212.5 & & & & 1297.7 & & & \\
\hline
\end{tabular}

Table 4 Corporate profit bridge for scenario firm

\begin{tabular}{llc}
\hline Measurement & Term & Global value \\
\hline Impact of changes in quantity sold globally & IQG & 134.8 \\
Impact of changes in prices globally & IPG & 76.8 \\
Impact of changes in variable costs globally & IVG & -12.7 \\
Impact of changes in product mix globally & IMG & -45.2 \\
Impact of changes in exchange rate globally & IEG & -68.5 \\
Change in profit & $\Delta$ RG & 85.2 \\
\hline
\end{tabular}

Which should be used will depend on what is the desired measurement. For instance, in annual reporting of corporate results to shareholders, the corporate profit bridge is likely to be more appropriate and meaningful for investors to evaluate the health of the corporation. Similarly, if pricing and/ or procurement and production are managed at the global level, the corporate profit bridge is likely to be more useful for evaluating the performance of these departments.

In contrast, if pricing and/or procurement and production decisions are managed within individual business units, the business unit profit bridge is likely to be more useful for evaluating the performance of these departments within individual business units.

More complex arrangements might imply both profit bridges are required for a full set of metrics. For instance, if pricing and/or procurement and production are managed at both the business unit and the global level, both profit bridges may be necessary to fully measure performance. In instances where individual business units are put within clusters of multiple business units and these clusters report to the global headquarters, one could imagine executives might require the construction of the profit bridge at three different levels.

\section{Example application}

An application of the corporate and business unit profit bridges to a hypothetical firm scenario with two countries, two products, and two time periods demonstrates and clarifies how the profit bridges can be used in practice.

The quantity sold, prices, variable costs in local currency, and exchange rates for both prices and variable costs for our scenario are shown in Table 3 for period 1 and 2 in business units US and CZ for products A and B.

In this scenario, the firm reports their annual report in the currency of US. The exchange rate with CZ has slowly degraded. The quantity sold in both countries has increased slightly. While prices are up in CZ, they were mixed in US. The variable costs in the US have increased for product $\mathrm{A}$ but remained flat for product $\mathrm{B}$, while the variable costs in $\mathrm{CZ}$ were increased for A but decreased for B.

Applying Eqs. 11 through 24, we measure the impact of various decisions and variations in business variables as shown in Table 4 and 5 for the Corporate and Business
Table 5 Business unit profit bridge for scenario firm

\begin{tabular}{llrrr}
\hline Measurement & Term & US & CZ & $\begin{array}{r}\text { Business } \\
\text { unit sum }\end{array}$ \\
\hline Impact of changes in quantity sold in business unit & $\mathrm{IQG}_{\mathrm{k}}$ & 95.9 & 39.3 & 135.3 \\
Impact of changes in prices in business unit & $\mathrm{IPG}_{\mathrm{k}}$ & -2.8 & 79.6 & 76.8 \\
Impact of changes in variable costs in business unit & $\mathrm{IVG}_{\mathrm{k}}$ & -26.1 & 13.3 & -12.7 \\
Impact of changes in product mix in business unit & $\mathrm{IMG}_{\mathrm{k}}$ & -26.1 & -19.7 & -45.7 \\
Impact of changes in exchange rate in business unit & $\mathrm{IEG}_{\mathrm{k}}$ & 0.0 & -68.4 & -68.4 \\
Change in profit & $\Delta \mathrm{RG}_{k}$ & 41.0 & 44.2 & 85.2 \\
\hline
\end{tabular}


Fig. 1 Corporate profit bridge

Fig. 2 US business unit Profit bridge

Fig. $3 \mathrm{CZ}$ business unit profit bridge
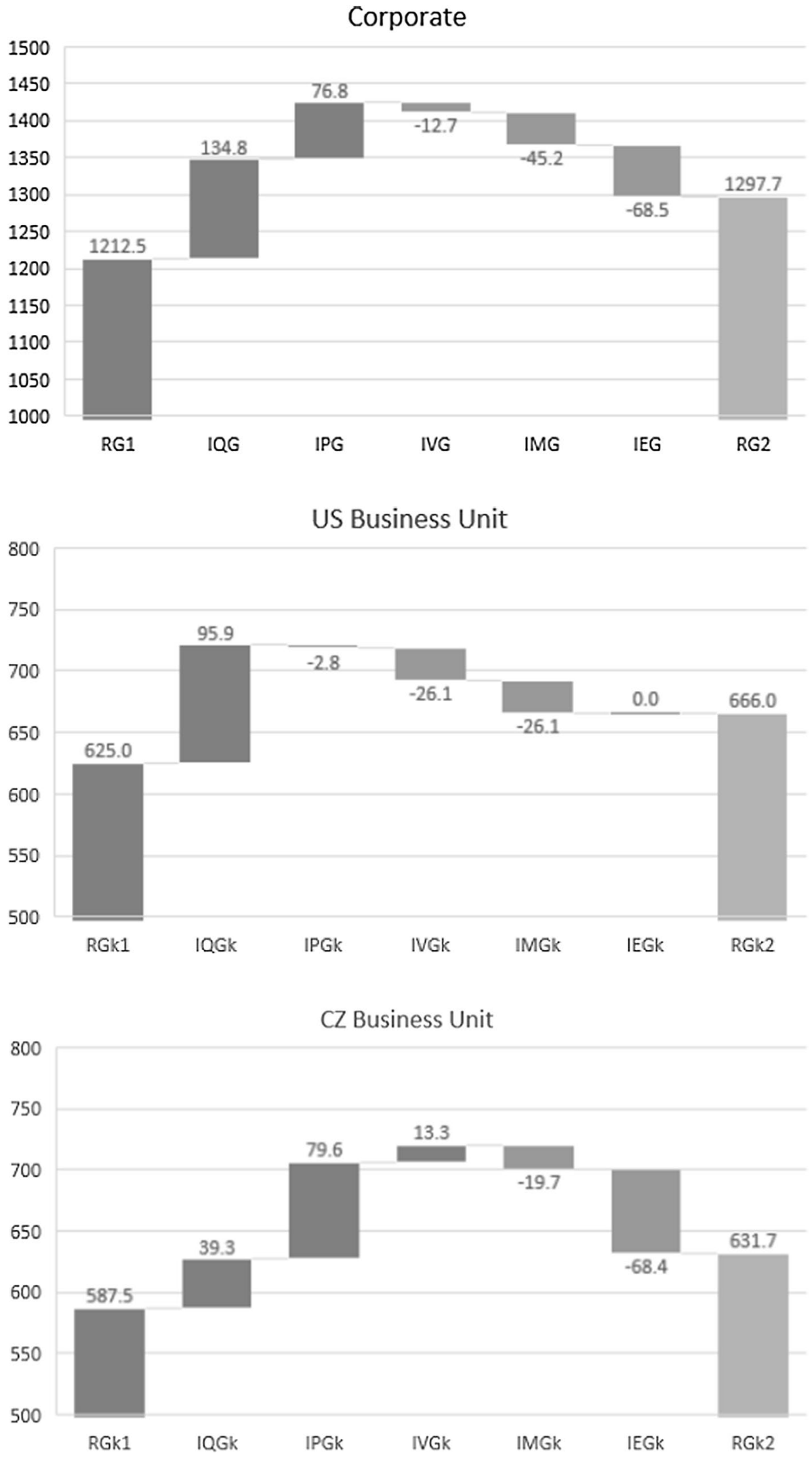
Fig. 4 Sum of business unit profit bridges

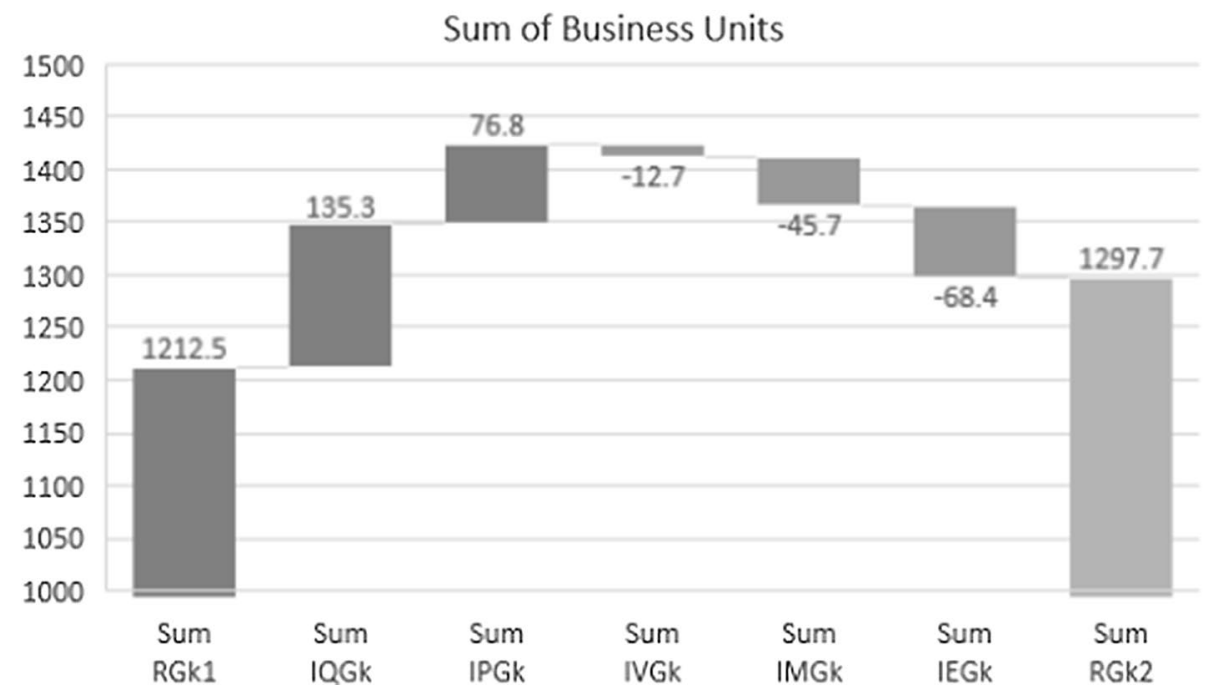

Units, respectively, rounded to one decimal point. Shown in Fig. 1, 2, 3, and 4 are the Global, US, CZ, and sum of business unit profit bridges.

For this scenario firm, the Global Profit Bridge attributes the profit increase primarily to an increase in the quantity sold and secondarily to an increase in prices. We also measure a harm to profits via unfavorable exchange rates, a poorer mix of offering sold, and an increase in variable costs, in that order.

At the business unit level, the business unit profit bridges provide greater detail. The US business unit achieved an overall increase in profits by improving the quantity sold while all other factors harmed profits. In contrast, the $\mathrm{CZ}$ business unit achieved an overall increase in profits primarily by increasing prices, secondarily by improving the quantity sold, and tertiarily by improving the mix of offering sold. Also, the CZ business unit did suffer from some increase in variable costs but largely due to unfavorable exchange rates. Fortunately, the increase in prices was greater than the impact of unfavorable exchange rates. Executives may conclude that they raised prices faster than the currency degraded.

In comparing the Corporate Profit Bridge to the Sum of Business Units Profit Bridges, we see slight differences as anticipated. While the overall picture of the state of the business remains consistent between the two approaches, details such as the impact of changes in quantity sold, mix, and exchange rate changes do appear. While both measurements are accurate, that which is most appropriate will depend on the context of the measurement in terms of decision-making.

\section{Discussion}

We have defined the equations and demonstrated their use for analyzing the source of changes in profits in a multinational corporation that distinctly measures the impact of changes in selling quantity, prices, variable costs, mix, and exchange rates. These equations flow from the normative decomposition of the profit bridge into the impact of changes in marketing variables published earlier.

Further adaptations can be made to these equations using a similar logic to make measurements in margin percentage, rather than total monetary contribution. Furthermore, if needed, one could use this approach to define a profit bridge where prices are set in relation to an index. Such an approach might be useful for companies managing products closely related to commodity-exchanged goods wherein the price of the offering is set in relation to an index of an underlying commodity. This situation may be found in chemicals, food processing, and other industries.

Such profit bridges, aka price-volume-mix analyses, are clearly of importance to shareholders and executives in decision-making. All decision makers are better served in making our measurements accurate, meaningful, and easy to interpret.

Open Access This article is licensed under a Creative Commons Attribution 4.0 International License, which permits use, sharing, adaptation, distribution and reproduction in any medium or format, as long as you give appropriate credit to the original author(s) and the source, provide a link to the Creative Commons licence, and indicate if changes were made. The images or other third party material in this article are included in the article's Creative Commons licence, unless indicated otherwise in a credit line to the material. If material is not included in the article's Creative Commons licence and your intended use is not permitted by statutory regulation or exceeds the permitted use, you will need to obtain permission directly from the copyright holder. To view a copy of this licence, visit http://creativecommons.org/licenses/by/4.0/. 


\section{References}

Albers, Sonke. 1998. A Framework for Analysis of Sources of Profit Contributions. International Journal of Research in Marketing XV 2: 109-122. https://doi.org/10.1016/S0167-8116(97)00038-4.

Calas, Robert. 1971. Variance Analysis in Profit Planning. Management Accounting VIII 1: 31.

Coskun, Umit. 2016. Variance Analysis (Volume, Mix, Price, Fx Rate). May 1. Retrieved January 28, 2021 from https://www.linkedin.com/pulse/variance-analy sis-volume-mix-price-fx-rate-umit-coskun/.

Early, J., Lai, D. and Johnson, J. 2013. Systems and Methods of a Causality Analyzer. United States Patent 8,412,598 B2.

Gurit 1HY 2014 Results, Slide 29. 2014. SlideShare.net. August 22. Retrieved September 9, 2020 from https://www.slideshare.net/ GuritGroup/gurit-investor-presentation-1-hy-2014-final.

Hulbert, J.M., and N.E. Toy. 1977. A Strategic Framework for Marketing Control. Journal of Marketing IV 2: 12.

Kyriba Corp. 2021. Kyriba's Currency Impact Report Reveals \$9.82 Billion in Total Quarterly FX Losses for European and North American Multinational Corporations. January 19. Retrieved February 15, 2021 from https://www.kyriba.com/company/newsr oom/kyriba-currency-impact-report-reveals-9-billion-quarterlyfx-losses-european-north-american-corporations/.

Kyriba. 2021. Kyriba Currency Impact Report Q3 2020.

LearnAccountingFinance.com. 2018. Explaining the Impact of Sales, Price, Volume, Mix, and Quantity Variances on Profit Margin (Current Year vs. Last Year). November 21. Retrieved January 27, 2021 from https://learnaccountingfinance.com/2018/11/21/ sales-variances/.

Lumber Liquidators Business Update. 2015. SEC.gov. March 12. Retrieved September 9, 2020 from https://www.sec.gov/Archives/ edgar/data/1396033/000114420415015501/v404301_ex99-1.htm.

Matchett, Geraldine. 2016. 2016 Report by the Managing Board. DSM. Retrieved September 9, 2020 from https://annualreport.dsm.com/ ar2016/en_US/6-6-profit-in-2016.html.

McIntyre, Edward W. 1976. A Note on the Joint Variance. The Accounting Review 51 (1): 151-155.

McIntyre, Edward W. 1978. The Joint Variance: A Reply. The Accounting Review LIII 2: 534-537.

Mitchell, Ted, and Howard Olsen. 2003. Marketing Control: Exogenous Aspects of Price Variance. Journal of Business \& Economics Research 1: 12. https://doi.org/10.19030/jber.v1i12.3074.

Noranda Aluminium Holding Corp First Quarter Conference Call, Slide 5. 2011. GetFilings.com. April 20. Retrieved September 9, $2020 \mathrm{from}$ http://www.getfilings.com/sec-filings/110420/Noran da-Aluminum-Holding-CORP_8-K/a6690961ex99_2.htm.

Piper, Roswell M. 1977. The Joint Variance: A Comment. The Accounting Review LII 2: 527-533.

Pirelli. 2016. Ebit Adjusted Bridge, Slide 3 \& 4. Pirelli.com. Retrieved September 9, 2020 from https://corporate.pirelli.com/corporate/ en-ww/investors/key-financials/profit-and-loss.
SA Transcripts. 2021. Johnson \& Johnson (JNJ) CEO Alex Gorsky on Q4 2020 Results - Earnings Call Transcript. January 26. Retrieved February 15, 2021 from https://seekingalpha.com/article/44010 77-johnson-johnson-jnj-ceo-alex-gorsky-on-q4-2020-results-earni ngs-call-transcript.

SA Transcripts. 2019. McDonald's Corporation (MCD) CEO Steve Easterbrook on Q2 2019 Results - Earnings Call Transcript. July 26. Retrieved February 15, 2021 from https://seekingalpha.com/ article/4278300-mcdonalds-corporation-mcd-ceo-steve-easte rbrook-on-q2-2019-results-earnings-call-transcript.

Shank, John K., Churchill, Neil C. 1977. Variance Management: A Management-Oriented Approach. Accounting Review VII (4): 950. Retrieved January 28, 2021 from https://search-ebscohostcom.ezproxy.depaul.edu/login.aspx?direct $=$ true $\& \mathrm{db}=\mathrm{bsh} \& \mathrm{AN}=$ $4505030 \&$ site $=$ ehost-live \&scope $=$ site. .

Smith, Tim J. 2021. Normative decomposition of the profit bridge into the impact of changes in marketing variables. Journal of Revenue and Pricing Management. https://doi.org/10.1057/ s41272-020-00278-8.

Szramiak, John. 2016. Here's a look at Harley-Davidson following rumors it might be acquired. Business Insider. July 11 . Retrieved September 9, 2020 from https://www.businessinsider.com/thestrength-of-harley-davidson-amid-acquisition-rumors-2016-7.

The Margin Bridge - The Power of Understanding Mix. Retrieved August 10, 2020 from https://thekinigroup.com/margin-bridgeunderstanding-mix/.

Vendavo. n.d. Vendavo Margin Bridge Analyzer. Retrieved August 10, 2020 from https://www.vendavo.com/resources/vendavo-marginbridge-analyzer-datasheet/.

Vizcaino, Maria Elena, and Liz McCormcik. 2020. Apple's \$1.5 Billion Headwind Adds FX to Litany of Company Woes. May 2. Retrieved February 15, 2021 from https://www.bloomberg.com/news/artic les/2020-05-02/apple-s-1-5-billion-headwind-adds-fx-to-litanyof-company-woes.

WS Atkins plc. SlideShare.net. Retrieved September 10, 2020 from https://www.slideshare.net/WSAtkins/2015-0611preliminaryresul tspresentaion.

Zurek, Thomas. 2013. The Hana EDW, Slide 21. Slideshare. SAP. June. Retrieved September 9, 2020 from https://es.slideshare.net/ukc4/ tdwi-hanaedwjun2013.

Publisher's Note Springer Nature remains neutral with regard to jurisdictional claims in published maps and institutional affiliations.

Tim J. Smith , Ph.D., is the founder and CEO of Wiglaf Pricing and Adjunct Professor of Marketing at DePaul University.

Kyle T. Westra is a Manager at Wiglaf Pricing.

Nathan L. Phipps is a Consultant at Wiglaf Pricing. 